\title{
Effects of particulate air pollution on blood pressure in a highly exposed population in Beijing, China: a repeated-measure study
}

Andrea Baccarelli ${ }^{1}$, Francesco Barretta ${ }^{2}$, Chang Dou ${ }^{3 *}$, Xiao Zhang ${ }^{4}$, John P McCracken ${ }^{1}$, Anaité Díaz ${ }^{5}$, Pier Alberto Bertazzi ${ }^{2}$, Joel Schwartz ${ }^{1}$, Sheng Wang ${ }^{6}$ and Lifang Hou ${ }^{4}$

\begin{abstract}
Background: Particulate Matter (PM) exposure is critical in Beijing due to high population density and rapid increase in vehicular traffic. PM effects on blood pressure (BP) have been investigated as a mechanism mediating cardiovascular risks, but results are still inconsistent. The purpose of our study is to determine the effects of ambient and personal PM exposure on BP.

Methods: Before the 2008 Olympic Games (June 15-July 27), we examined 60 truck drivers and 60 office workers on two days, 1-2 weeks apart $(n=240)$. We obtained standardized measures of post-work BP. Exposure assessment included personal $\mathrm{PM}_{2.5}$ and Elemental Carbon (EC, a tracer of traffic particles) measured using portable monitors during work hours; and ambient $\mathrm{PM}_{10}$ averaged over 1-8 days pre-examination. We examined associations of exposures (exposure group, personal $\mathrm{PM}_{2.5} / \mathrm{EC}$, ambient $\mathrm{PM}_{10}$ ) with BP controlling for multiple covariates.

Results: Mean personal $\mathrm{PM}_{2.5}$ was $94.6 \mu \mathrm{g} / \mathrm{m}^{3}(\mathrm{SD}=64.9)$ in office workers and 126.8 (SD = 68.8) in truck drivers (p-value < 0.001). In all participants combined, a $10 \mu \mathrm{g} / \mathrm{m}^{3}$ increase in 8-day ambient PM 10 was associated with BP increments of $0.98(95 \% \mathrm{Cl} 0.34 ; 1.61$; p-value $=0.003), 0.71(95 \% \mathrm{Cl} 0.18 ; 1.24 ; \mathrm{p}$-value $=0.01)$, and $0.81(95 \% \mathrm{Cl} 0.31$; 1.30; $\mathrm{p}$-value $=0.002) \mathrm{mmHg}$ for systolic, diastolic, and mean BP, respectively. BP was not significantly different between the two groups ( $p$-value > 0.14). Personal PM $_{2.5}$ and EC during work hours were not associated with increased BP.

Conclusions: Our results indicate delayed effects of ambient $\mathrm{PM}_{10}$ on BP. Lack of associations with exposure groups and personal $\mathrm{PM}_{2.5}$ /EC indicates that PM effects are related to background levels of pollution in Beijing, and not specifically to work-related exposure.
\end{abstract}

Keywords: Particulate Matter, Personal Monitoring, Blood Pressure, Traffic Pollution, China

\section{Background}

Epidemiologic studies have consistently associated shortterm increases in exposure to air particles with higher rates of hospitalization and mortality for cardiovascular disease in the hours and days following exposure peaks [1]. Airborne particulate matter $\leq 2.5 \mu \mathrm{m}\left(\mathrm{PM}_{2.5}\right)$ or $\leq 10$ $\mu \mathrm{m}\left(\mathrm{PM}_{10}\right)$ in aerodynamic diameter can be inhaled and deposited in the upper and lower airways [2]. Several pathways have been proposed to link PM inhalation

\footnotetext{
* Correspondence: changdou2004@sohu.com

${ }^{3}$ Deptartment of Safety Engineering, China Institute of Industrial Health

No.45 Zengguang Rd., Haidian District, Beijing 100048, China

Full list of author information is available at the end of the article
}

with these acute cardiovascular effects, including inflammatory, endothelial, and autonomic responses [1]. However, the patho-physiological changes linking air pollution inhalation to cardiovascular events have not been fully elucidated. Elevated BP is an established risk factor for coronary heart disease and stroke, and may be implicated in the association of short-term PM exposure with cardiovascular disease. An increase as small as 1 $\mathrm{mmHg}$ in usual systolic BP is estimated to increase by $2-4 \%$ the risk of death due to cardiovascular disease $[3,4]$. Studies have examined air particle exposures in relation to $\mathrm{BP}$ elevation with results showing several positive [5-14], but also some negative [15-18] and null 
associations [19-21]. Several of the previous investigations did not have BP as the primary outcome and as such were not designed with the explicit intention to evaluate the association between PM and BP [1].

Beijing has been ranked as one of the 15 cities with the highest levels of air pollution worldwide [22]. Traffic-derived PM is critical in Beijing due to very high population density and rapid increase in vehicular traffic [23]. Transported particles from industrial sources and windblown dust are also major sources of pollution [23]. Examining the effects of high levels of PM such as those found in Beijing may help to characterize changes in BP that might not be consistently demonstrated in populations with lower exposures.

In the present study, we investigated 60 truck drivers and 60 indoor workers in Beijing to evaluate whether either typical or short-term exposure to air particles is associated with effects on BP. To enhance power to identify effects on BP, we studied each subject on two different examination days, 1-2 weeks apart, and assessed exposure using personal measures of $\mathrm{PM}_{2.5}$ and Elemental Carbon (EC, a surrogate for traffic particles) on the day of the exam and ambient levels of $\mathrm{PM}_{10}$ up to eight days before the exam.

\section{Methods}

\section{Study population and design}

The Beijing Truck Driver Air Pollution Study (BTDAS) was conducted between June 15 to July 27, 2008, shortly before the Beijing Olympic Games. The BTDAS included 60 truck drivers and 60 indoor office workers. Because PM levels are highly variable on a day-to-day basis, we examined all subjects on two workdays separated by 1-2 weeks. Both truck drivers and office workers worked and lived in the Beijing metropolitan area and had been on their current jobs for $\geq$ two years. The two groups were matched by sex, smoking status and education, and partially matched (5-year intervals) by age. In-person questionnaire-based interviews were conducted to collect information on demographics, lifestyle, and other exposures. Information on time-varying factors, including tea, alcohol, and smoking, was obtained for past usual exposure, as well as on each examination day. Individual written informed consent and Institutional Review Board approval was obtained prior to the study.

\section{Personal exposure measurements}

We measured personal $\mathrm{PM}_{2.5}$ on both examination days using gravimetric samplers worn by the study subjects during the eight hours of work. The sampler was carried in a belt pack with the inlet clipped near the breathing zone. Each sampler setup included an Apex pump (Casella Inc., Bedford, UK), a Triplex Sharp-Cut Cyclone
(BGI Inc., Waltham, Massachusetts), and a 37-mm Teflon filter placed on top of a drain disc and inside a metal filter holder. The filters were kept under atmosphere-controlled conditions before and after sampling and were weighed with a microbalance (Mettler-Toledo Inc., Columbus, Ohio, USA). A time-weighted average of $\mathrm{PM}_{2.5}$ concentration was recorded by dividing the change in filter weight before and after sampling by the volume of air sampled. We found high reproducibility of $\mathrm{PM}_{2.5}$ measures $(\mathrm{r}=0.944)$ in replicate measures on a subset of 24 subjects who wore two monitors at the same time (Figure 1). The blackness of the same filters used to measure $\mathrm{PM}_{2.5}$ was assessed using an EEL Model M43D Smokestain Reflectometer, applying the standard black-smoke index calculations of the absorption coefficients based on reflectance [24]. We assumed a factor of 1.0 for converting the absorption coefficient to EC mass $[25,26]$, which was then divided by the sampled air volume to calculate average EC exposure concentration [24]. EC is a combustion by-product contained in PM that has been used as a surrogate measure for PM from gasoline- and especially diesel-powered motor vehicles [25].

\section{Ambient $\mathrm{PM}_{10}$ data}

Ambient $\mathrm{PM}_{10}$ data during the study period were obtained from the Beijing Municipal Environmental Bureau (http://www.bjepb.gov.cn/air2008/Air.aspx). We used daily averages of $\mathrm{PM}_{10}$ computed from data obtained from 27 monitoring stations to estimate the average $\mathrm{PM}_{10}$ level in Beijing. The monitoring stations are distributed across the area to represent Beijing city. We used ambient $\mathrm{PM}_{10}$ data to test the hypothesis that the association between particles and blood pressure is with a longer-term average exposure than with the personal monitors. We used multiple averaging time windows, which included 1-day mean (24 hour average of the day before the examination), as well as 2-day, 5-day, and 8-day means (i.e., average of the 2-8 days before the examination). We obtained daily outdoor temperature data for Beijing city from the National Oceanic and Atmospheric Administration online database [27].

\section{Seated BP and heart rate measurements}

Seated BP and heart rate were measured by a trained research assistant at the end of each work day (i.e., between 4-6 pm) after a full five minutes of rest. Heart rate was taken in the sitting position by measuring it over a 30 -second period by pulse palpation at the radial artery. Two heart rate measurements were taken and their average was recorded. A standardized protocol for $\mathrm{BP}$ measurements was used according to the recommendations issued by the American Heart Association [28]. $\mathrm{BP}$ was measured using a mercury sphygmomanometer 


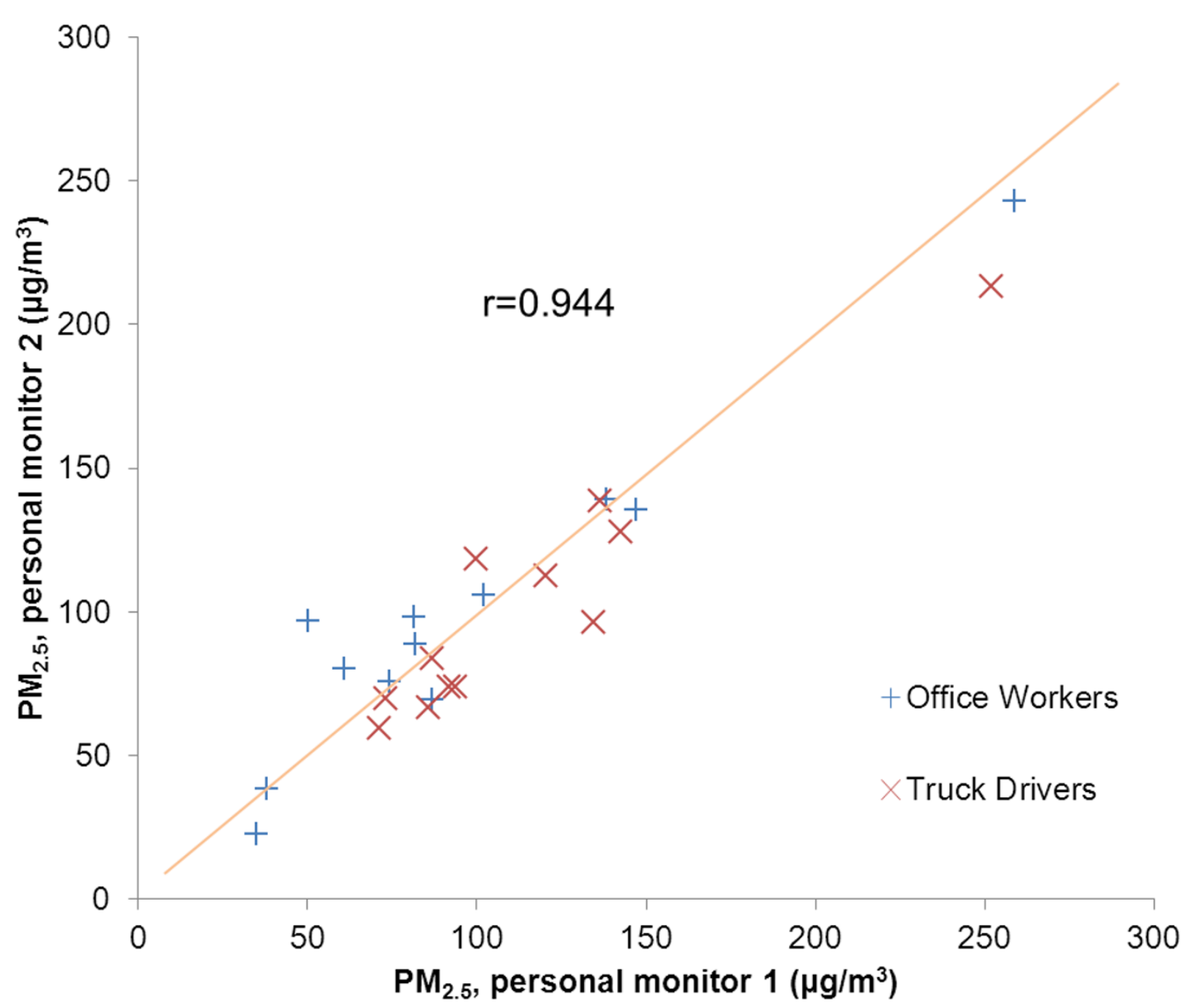

Figure 1 Measures of $\mathrm{PM}_{2.5}$ from two independent personal monitors. Measures of $\mathrm{PM}_{2.5}$ from two independent personal monitors worn at the same time by a subset of 12 study subjects to test the accuracy of the measurements. The scatter plot shows the high correlation ( $r=0.944)$ between monitor 1 and monitor 2 .

on the right arm using appropriate cuff sizes. All readings were made to the nearest even digit by rounding up if necessary. Three readings were taken and BP was calculated from the average of the second and third readings. After each reading, the research assistant waited at least one minute before proceeding to the next reading. Mean arterial pressure was approximated from systolic and diastolic BP by adding $1 / 3$ of the difference between systolic and diastolic BP to the value of diastolic BP. Pulse pressure was defined as the difference between systolic and diastolic BP.

\section{Statistical analysis}

Standard descriptive statistics were used to describe the characteristics of truck drivers and office workers. For variables considered constant within-subjects between the two examination days, such as age, sex, and usual smoking habits, differences in participant characteristics between the two groups were tested using Student's ttests and Fisher's exact tests. For variables that varied between the two examination days, such as tea consumption or number of cigarettes smoked on that day, we evaluated differences between the two groups using mixed-effect regression models (PROC MIXED in SAS 9.2, SAS Institute Inc., Cary, NC). Similarly, we used mixed-effect models to regress $\mathrm{BP}$ or heart rate variables on group (0, office workers; 1 , truck drivers) to test for differences between groups and estimate group-specific means and standard deviations (SDs). For BP or heart rate variables, we fitted unadjusted models as well as models adjusted for variables either not matched or not completely matched by design between the two groups, i.e. age (continuous), BMI (continuous), cigarettes smoked during study time (continuous), pack-years of 
smoking (continuous), tea consumption during study time (yes/no), usual alcohol drinking (yes/no), work hours/week (continuous) and day of the week (one indicator variable per day). The mixed-effect regression models were:

$$
y_{i j}=\beta_{0}+\beta_{1} \text { (Group) }+\beta_{2} X_{2 j}+\ldots+\beta_{n} X_{n j}+\xi_{i j}+e_{i j}
$$

where $\beta_{0}$ is the overall intercept; $\beta_{1}$ is the regression coefficient for the group; $\beta_{2} \ldots \beta_{n}$ are the regression coefficients for the covariates included in multivariate models; $\xi_{i j}$ is the random effect for the subject; $j$ represents the subject; $i$ identifies the workday and $e_{i j}$ is the residual error term.

We evaluated the associations of personal $\mathrm{PM}_{2.5}$, personal EC, and ambient $\mathrm{PM}_{10}$ variables (1-day, 2-day, 5day, or 8-day mean) with BP variables or heart rate using mixed-effect models adjusted for age (continuous), sex (male, female), BMI (continuous), day of the week (one indicator variable per day), smoking (never, former, current), cigarettes smoked during study time (continuous), pack-years of smoking (continuous), work hours/ week (continuous), tea consumption during study time (yes/no), usual alcohol drinking (yes/no) and outdoor temperature (continuous). To optimize power, we conducted primary analyses on the association of exposure measures and BP or heart rate by fitting these models in all participants combined. Secondarily, we evaluated associations in office workers or truck drivers separately. For outdoor temperature, we used averaging times (one to eight days) to match the averaging times used for the air particle variables. The mixed-effect model was:

$$
y_{i j}=\beta_{0}+\beta_{1}(\operatorname{Exp})_{i}+\beta_{2}(\mathrm{Temp})_{i}+\beta_{3} X_{3 i}+\ldots+\beta_{n} X_{n i}+\xi_{i j}+e_{i j}
$$

where $\beta_{0}$ is the overall intercept; $\beta_{1}$ is the regression coefficient for exposure variable $\left(\mathrm{EC}, \mathrm{PM}_{2.5}\right.$, or $\left.\mathrm{PM}_{10}\right)$; $\beta_{2}$ is the regression coefficient of the mean temperature of the days of interest; $\beta_{3} \ldots \beta_{n}$ are the regression coefficients for the covariates included in multivariate models; $\xi_{i j}$ is the random effect for the subject; $j$ represents the subject; $i$ represents the examination day, and $e_{i j}$ is the residual error term. All tests were two-sided and an alpha level of less than 0.05 was considered significant.

\section{Results}

\section{Characteristics of the study participants}

The characteristics of the 60 office workers and 60 truck drivers are shown in Table 1 . Truck drivers were moderately, but significantly older than office workers. Truck drivers had higher BMI, reported a higher number of pack-years of smoking, smoked more cigarettes during the study time, and included a higher proportion of usual alcohol drinkers. A larger proportion of truck drivers reported tea consumption during the study period.

\section{Personal exposure and ambient levels of air particles}

Table 2 shows the levels and distribution of personal time-weighted average exposure to $\mathrm{PM}_{2.5}$ and EC estimated during eight work hours, as well as the mean levels of ambient $\mathrm{PM}_{10}$ on the days before the examination days. Average personal $\mathrm{PM}_{2.5}$ was $126.8 \mu \mathrm{g} / \mathrm{m}^{3}$ in truck drivers and $94.6 \mu \mathrm{g} / \mathrm{m}^{3}$ for office workers (p-value $<0.001)$. Average personal EC was $17.2 \mu \mathrm{g} / \mathrm{m}^{3}$ in truck drivers and $13.0 \mu \mathrm{g} / \mathrm{m}^{3}$ for office workers (p-value < 0.001). As expected, the levels of ambient $\mathrm{PM}_{10}$ in the city of Beijing on the days before the examinations (1-8 day means) did not differ between truck drivers and office workers (Table 2).

\section{Blood pressure and heart rate in truck drivers and office workers}

In unadjusted analyses, truck drivers showed higher diastolic BP than office workers ( $\mathrm{p}$-value $=0.03$ ), but no significant differences in systolic BP, mean arterial BP, pulse pressure, and heart rate (Table 3). Analyses adjusted by age, BMI, pack-years of smoking, number of cigarettes smoked and tea consumption during the time of the study, usual alcohol drinking, day of the week, and work hours/week did not show any statistically significant difference in systolic, diastolic, mean, or heart rate (Table 3 ). In the covariate-adjusted model, average pulse pressure in truck drivers was marginally higher than in office workers ( $p$-value $=0.07$ ).

\section{Associations of personal $\mathrm{PM}_{2.5}$, personal EC, and ambient $\mathrm{PM}_{10}$ with blood pressure and heart rate}

In analyses conducted on all participants combined, personal $\mathrm{PM}_{2.5}$ and EC measured during work hours did not show any significant association with BP measures or heart rate (Table 4). Also, the levels of ambient $\mathrm{PM}_{10}$ on the day before the examinations were not significantly associated with BP measures or heart rate. In all participants combined, BP increased in association with the levels of ambient $\mathrm{PM}_{10}$ averaged over five or eight days before the examinations. A $10 \mu \mathrm{g} / \mathrm{m}^{3}$ increase in the 5-day mean of ambient $\mathrm{PM}_{10}$ was associated with an average increase of $0.63 \mathrm{mmHg}$ in systolic BP $(95 \% \mathrm{CI}$ $0.09 ; 1.16$; p-value $=0.02), 0.50 \mathrm{mmHg}$ in diastolic BP $(95 \%$ CI 0.06 ; $0.95 ; \mathrm{p}$-value $=0.03)$, and $0.55 \mathrm{mmHg}$ in mean arterial pressure $(95 \% \mathrm{CI} 0.13 ; 0.96 ; \mathrm{p}$-value $=$ $0.01)$. A $10 \mu \mathrm{g} / \mathrm{m}^{3}$ increase in the 8 -day mean of ambient $\mathrm{PM}_{10}$ was associated with an average increase of $0.98 \mathrm{mmHg}$ in systolic BP $(95 \%$ CI $0.34 ; 1.61 ; \mathrm{p}$-value = $0.003), 0.71 \mathrm{mmHg}$ in diastolic BP (95\%CI 0.18; 1.24 ; pvalue $=0.01)$, and $0.81 \mathrm{mmHg}$ in mean arterial pressure 
Table 1 Characteristics of the Study Participants

\begin{tabular}{|c|c|c|c|}
\hline & $\begin{array}{l}\text { Office Workers } \\
\quad(n=60)\end{array}$ & $\begin{array}{l}\text { Truck Drivers } \\
\quad(n=60)\end{array}$ & p-value ${ }^{a}$ \\
\hline \multicolumn{4}{|l|}{ Sex, n (\%) } \\
\hline Male & $40(66.67)$ & $40(66.67)$ & \\
\hline Female & $20(33.33)$ & $20(33.33)$ & 1.00 \\
\hline Age [Years], mean \pm SD & $30.27 \pm 7.96$ & $33.53 \pm 5.65$ & 0.004 \\
\hline \multicolumn{4}{|l|}{ Smoking, n (\%) } \\
\hline Never smoker & $35(58.33)$ & $34(56.67)$ & \\
\hline Ex-smoker & $2(3.33)$ & $2(3.33)$ & \\
\hline Actual smoker & $23(38.33)$ & $24(40)$ & 1.00 \\
\hline Pack-years of smoking $\left[\mathrm{kg} / \mathrm{m}^{2}\right]$, mean $\pm \mathrm{SD}^{\mathrm{b}}$ & $2.87 \pm 3.59$ & $11.7 \pm 11.2$ & $<0.001$ \\
\hline Cigarettes smoked during the study time ${ }^{c}$ [cigarettes/day], mean \pm SD & $2.85 \pm 5.21$ & $6.39 \pm 9.41$ & $<0.001^{\mathrm{c}}$ \\
\hline BMI $\left[\mathrm{kg} / \mathrm{m}^{2}\right]$, mean $\pm \mathrm{SD}$ & $22.76 \pm 3.38$ & $24.27 \pm 3.21$ & 0.01 \\
\hline \multicolumn{4}{|l|}{ Tea consumption during the time of the study ${ }^{c}, \mathrm{n}(\%)$} \\
\hline No & $109(90.83)$ & $86(71.67)$ & \\
\hline Yes & $11(9.17)$ & $34(28.33)$ & $0.003^{c}$ \\
\hline \multicolumn{4}{|l|}{ Day of the week ${ }^{\mathrm{c}}, \mathrm{n}(\%)$} \\
\hline Monday & $16(13.33)$ & $19(15.83)$ & \\
\hline Tuesday & $18(15)$ & $13(10.83)$ & \\
\hline Wednesday & $14(11.67)$ & $15(12.5)$ & \\
\hline Thursday & $15(12.5)$ & $20(16.67)$ & \\
\hline Friday & $17(14.17)$ & $19(15.83)$ & \\
\hline Saturday & $18(15)$ & $16(13.33)$ & \\
\hline Sunday & $22(18.33)$ & $18(15)$ & $0.88^{c}$ \\
\hline \multicolumn{4}{|l|}{ Usual alcohol drinking, n (\%) } \\
\hline Yes & $14(23.33)$ & $31(51.67)$ & \\
\hline No & $46(76.67)$ & $29(48.33)$ & 0.002 \\
\hline
\end{tabular}

a P-values were calculated using Student's t-test and Fisher's exact test for continuous and categorical variables, respectively, except for the variables indicated at the footnote ${ }^{\mathrm{c}}$ below.

${ }^{\mathrm{b}}$ Only current or former smokers.

${ }^{c}$ Cumulative of the two study days. Based on 240 total observations (120 study days for office workers and 120 study days for truck drivers). P-values were obtained from mixed-effect regression models.

$(95 \%$ CI $0.31 ; 1.30 ; \mathrm{p}$-value $=0.002)$. In all subjects combined, personal $\mathrm{PM}_{2.5}$, personal EC, and ambient $\mathrm{PM}_{10}$ were not associated with heart rate (Table 4).

Separate analyses in office workers and truck drivers showed that the associations of the 5- and 8-day means of ambient $\mathrm{PM}_{10}$ with $\mathrm{BP}$ were found in each of the two groups (Table 4). Associations of ambient $\mathrm{PM}_{10}$ with systolic BP appeared moderately stronger in truck drivers (5-day and 8-day), whereas associations of ambient $\mathrm{PM}_{10}$ with diastolic $\mathrm{BP}$ appeared stronger in office workers, particularly for the 8-day mean (Table 4). In addition, in office workers we observed an unexpected negative association of personal EC levels with diastolic $\mathrm{BP}(\mathrm{p}$-value $=0.01)$ and mean arterial pressure $(\mathrm{p}$-value $=0.01)$. In truck drivers, we found that the 8-day average ambient $\mathrm{PM}_{10}$ levels were associated with significant increases in pulse pressure $(\mathrm{p}$-value $=0.01)$ and heart rate $(\mathrm{p}$-value $=0.02)$. In truck drivers, the 5 -day average ambient $\mathrm{PM}_{10}$ levels were also marginally associated with increased heart rate $(\mathrm{p}$-value $=0.05)$. To evaluate the potential masking of air pollution effects by smoking, we conducted additional analyses stratified by current smoking. In the additional files, we report the results stratified by current smoking for the associations of personal $\mathrm{PM}_{2.5}$, personal $\mathrm{EC}$, and ambient $\mathrm{PM}_{10}$ with BP and heart rate for the entire study group (Table S1, Additional file 1), as well as for office workers (Table S2, Additional file 1) or truck drivers (Table S3, Additional file 1). Overall, these analyses do not suggest that the effects of the exposures were different among current or non-current smokers.

\section{Discussion}

In this study of truck drivers and office workers in Beijing, China, we showed increases in systolic, diastolic, and mean arterial BP associated with the levels of 
Table 2 Levels of personal exposure to $\mathrm{PM}_{2.5}$ and Elemental Carbon (EC) during work hours, and of ambient $\mathrm{PM} \mathrm{M}_{10}$ and outdoor temperature on the days before examination

\begin{tabular}{|c|c|c|c|c|c|c|c|c|c|c|c|c|c|c|c|c|c|}
\hline \multirow[t]{2}{*}{ Time window } & \multicolumn{7}{|c|}{ Office Workers } & \multicolumn{10}{|c|}{ Truck Drivers } \\
\hline & $\mathbf{N}$ & Mean & SD & 10pct & $25 p c t$ & Median & $75 p c t$ & 90 pct & $\mathbf{N}$ & Mean & SD & 10pct & $25 p c t$ & Median & $75 p c t$ & 90pct & p-value \\
\hline \multicolumn{18}{|c|}{ Personal $\mathrm{PM}_{2.5}{ }^{\mathrm{a}}\left(\mu \mathrm{g} / \mathrm{m}^{3}\right)$ on the examination days, from personal monitors } \\
\hline 8 hours & 120 & 94.6 & 64.9 & 22.4 & 48.5 & 86.2 & 126.6 & 183.4 & 119 & 126.8 & 68.8 & 46.3 & 73. & 116 & 160.5 & 213.9 & $<0.001$ \\
\hline \multicolumn{18}{|c|}{ Personal $\mathrm{EC}^{\mathrm{a}}\left(\mu \mathrm{g} / \mathrm{m}^{3}\right)$ on the examination days, from personal monitors } \\
\hline 8 hours & 118 & 13.0 & 4.0 & 7.1 & 10.0 & 13.2 & 15.8 & 18.4 & 120 & 17.2 & 6.6 & 9.2 & 12.9 & 16.7 & 20.9 & 26.1 & $<0.001$ \\
\hline \multicolumn{18}{|c|}{ Ambient $\mathrm{PM}_{10}\left(\mu \mathrm{g} / \mathrm{m}^{3}\right)$ from ambient monitors on the days prior to the study days } \\
\hline 1-day mean & 120 & 121.5 & 47.8 & 72.0 & 82.0 & 118.0 & 146.0 & 186.0 & 120 & 119.5 & 51.2 & 64.0 & 82.0 & 118.0 & 142.0 & 188.0 & 0.76 \\
\hline 2-day mean & 120 & 121.6 & 38.0 & 74.5 & 93.0 & 125.0 & 146.0 & 173.0 & 120 & 119.3 & 40.3 & 66.0 & 91.0 & 120.0 & 144.0 & 157.0 & 0.64 \\
\hline 5-day mean & 120 & 119.5 & 26.9 & 80.7 & 105.6 & 119.6 & 138.0 & 148.8 & 120 & 118.2 & 25.6 & 81.0 & 96.8 & 119.6 & 136.8 & 144.0 & 0.69 \\
\hline 8-day mean & 120 & 119.5 & 23.0 & 84.9 & 101.8 & 119.9 & 141.5 & 146.5 & 120 & 120.2 & 21.5 & 95.6 & 102.8 & 120.4 & 139.0 & 146.3 & 0.81 \\
\hline \multicolumn{18}{|c|}{ Outdoor temperature $\left({ }^{\circ} \mathrm{C}\right)$ on the days prior to the study days } \\
\hline 1-day mean & 120 & 25.1 & 2.7 & 22.0 & 23.0 & 26.0 & 28.0 & 29.0 & 120 & 25.3 & 2.6 & 22.0 & 23.0 & 26.0 & 28.0 & 29.0 & 0.75 \\
\hline 2-day mean & 120 & 25.2 & 2.3 & 22.0 & 23.0 & 25.5 & 27.5 & 28.0 & 120 & 25.0 & 2.7 & 22.0 & 23.0 & 25.3 & 27.0 & 28.0 & 0.56 \\
\hline 5-day mean & 120 & 25.1 & 1.8 & 22.6 & 23.6 & 25.6 & 26.4 & 27.2 & 120 & 24.9 & 1.7 & 22.6 & 23.2 & 25.4 & 26.4 & 27.0 & 0.30 \\
\hline 8-day mean & 120 & 25.0 & 1.4 & 23.1 & 24.0 & 24.6 & 26.4 & 27.0 & 120 & 24.9 & 1.4 & 23.1 & 23.6 & 24.5 & 26.3 & 26.9 & 0.34 \\
\hline
\end{tabular}

${ }^{a}$ Measured during the work hours of examination days using light-weight personal monitors.

ambient $\mathrm{PM}_{10}$ averaged over five and eight days before the BP examination days. We found no significant positive associations of $\mathrm{BP}$ with personal measures of $\mathrm{PM}_{2.5}$ and EC taken during work hours on the day of the examination, nor with ambient $\mathrm{PM}_{10}$ averaged over 1-2 days before the examination days. Taken together, these results suggest that comparatively higher levels of PM exposure exert effects on BP that appear with a delay or possibly require 5-8 days to build up and become detectable. BP was higher among truck drivers than office workers, but there was no statistically significant difference after adjustment for potential confounders. Therefore, our results do not provide support for effects of work-related exposure to air particles on BP.

Previous studies that showed positive associations between PM exposure and BP estimated that a $10 \mu \mathrm{g} /$ $\mathrm{m}^{3}$ increase in $\mathrm{PM}_{2.5}$ is expected to raise BP by approximately 1-5 mmHg, as summarized by Brook and Rajagopalan [29]. In the present study, we found that a $10 \mu \mathrm{g} /$ $\mathrm{m}^{3}$ increase in average ambient $\mathrm{PM}_{10}$ in the eight days before the examinations was associated with increases in BP equal to $0.71-0.98 \mathrm{mmHg}$. These estimates need to

Table 3 Blood pressure and heart rate in office workers and truck drivers

\begin{tabular}{|c|c|c|c|c|c|}
\hline & & orkers & & rivers & \\
\hline & $\mathrm{N}$ & Mean \pm SD & $\mathrm{N}$ & Mean \pm SD & p-value \\
\hline \multicolumn{6}{|l|}{ Unadjusted } \\
\hline Systolic blood pressure (mmHg) & 120 & $115.3 \pm 11.7$ & 120 & $116.3 \pm 13.3$ & 0.56 \\
\hline Diastolic blood pressure $(\mathrm{mmHg})$ & 120 & $77.6 \pm 8.3$ & 120 & $80.2 \pm 9.7$ & 0.03 \\
\hline Mean Arterial pressure $(\mathrm{mmHg})$ & 120 & $90.2 \pm 8.6$ & 120 & $92.3 \pm 10.5$ & 0.10 \\
\hline Pulse pressure $(\mathrm{mmHg})$ & 120 & $37.7 \pm 9.0$ & 120 & $36.1 \pm 7.4$ & 0.13 \\
\hline Heart Rate (beats/min) & 120 & $78.3 \pm 10.4$ & 120 & $79.3 \pm 10.9$ & 0.49 \\
\hline
\end{tabular}

Adjusted for age, BMI, pack-years, number of cigarettes and tea consumption during the time of the study, usual alcohol drinking, work hours/week, and day of the week ${ }^{\mathrm{a}}$

\begin{tabular}{llllll}
\hline Systolic blood pressure $(\mathrm{mmHg})$ & 120 & $118.9 \pm 1.7$ & 120 & $115.4 \pm 1.5$ & 0.14 \\
\hline Diastolic blood pressure $(\mathrm{mmHg})$ & 120 & $79.9 \pm 1.2$ & 120 & $79.2 \pm 1.1$ & 0.70 \\
\hline Mean Arterial pressure $(\mathrm{mmHg})$ & 120 & $92.8 \pm 1.2$ & 120 & $91.2 \pm 1.1$ & 0.36 \\
\hline Pulse pressure $(\mathrm{mmHg})$ & 120 & $39.3 \pm 1.2$ & 120 & $36.3 \pm 1.1$ & 0.07 \\
\hline Heart Rate (beats/min) & 120 & $78.9 \pm 1.5$ & 120 & $79.6 \pm 1.3$ & 0.72
\end{tabular}

${ }^{\mathrm{a}}$ Office workers and truck drivers were matched by sex and smoking (never, former, current). Adjusted means were computed by holding covariates fixed at their average values. 
Table 4 Effects of a $10 \mu \mathrm{g}$ increase in air particles on blood pressure and heart rate, by group and on all subjects combined $^{\mathrm{a}}$

\begin{tabular}{|c|c|c|c|c|c|c|c|c|c|}
\hline & \multicolumn{3}{|c|}{ All Subjects (obs $=240^{b}$ ) } & \multicolumn{3}{|c|}{ Office Workers (obs $=120^{\circ}$ ) } & \multicolumn{3}{|c|}{ Truck Drivers (obs $=120^{d}$ ) } \\
\hline & $\beta$ & $(95 \% \mathrm{Cl})$ & p-value & $\beta$ & $(95 \% \mathrm{Cl})$ & p-value & $\beta$ & $(95 \% \mathrm{Cl})$ & p-value \\
\hline \multicolumn{10}{|l|}{ Systolic blood pressure $(\mathrm{mmHg})$} \\
\hline Personal PM 2.5 (work hours) & -0.01 & $(-0.18 ; 0.17)$ & 0.94 & -0.06 & $(-0.29 ; 0.18)$ & 0.64 & 0.15 & $(-0.16 ; 0.46)$ & 0.33 \\
\hline Personal EC (work hours) & -0.29 & $(-2.32 ; 1.73)$ & 0.77 & -2.54 & $(-6.39 ; 1.31)$ & 0.19 & 1.23 & $(-1.53 ; 3.99)$ & 0.38 \\
\hline Ambient $\mathrm{PM}_{10}$ (1-day mean) & 0.20 & $(-0.05 ; 0.45)$ & 0.11 & 0.10 & $(-0.26 ; 0.46)$ & 0.57 & 0.24 & $(-0.13 ; 0.60)$ & 0.20 \\
\hline Ambient $\mathrm{PM}_{10}$ (2-day mean) & 0.26 & $(-0.08 ; 0.59)$ & 0.14 & -0.05 & $(-0.53 ; 0.44)$ & 0.85 & 0.47 & $(-0.04 ; 0.97)$ & 0.07 \\
\hline Ambient $\mathrm{PM}_{10}$ (5-day mean) & 0.63 & $(0.09 ; 1.16)$ & 0.02 & 0.08 & $(-0.80 ; 0.95)$ & 0.86 & 0.97 & $(0.15 ; 1.78)$ & 0.02 \\
\hline Ambient $\mathrm{PM}_{10}$ (8-day mean) & 0.98 & $(0.34 ; 1.61)$ & 0.003 & 0.53 & $(-0.44 ; 1.50)$ & 0.28 & 1.31 & $(0.32 ; 2.31)$ & 0.01 \\
\hline \multicolumn{10}{|l|}{ Diastolic blood pressure $(\mathrm{mmHg})$} \\
\hline Personal PM 2.5 (work hours) & 0.04 & $(-0.11 ; 0.19)$ & 0.57 & 0.00 & $(-0.21 ; 0.22)$ & 0.97 & 0.09 & $(-0.14 ; 0.33)$ & 0.42 \\
\hline Personal EC (work hours) & -1.26 & $(-2.94 ; 0.43)$ & 0.14 & -4.52 & $(-7.87 ;-1.16)$ & 0.01 & 0.23 & $(-1.84 ; 2.3)$ & 0.83 \\
\hline Ambient $\mathrm{PM}_{10}$ (1-day mean) & 0.18 & $(-0.03 ; 0.39)$ & 0.09 & 0.11 & $(-0.21 ; 0.43)$ & 0.49 & 0.24 & $(-0.03 ; 0.51)$ & 0.08 \\
\hline Ambient $\mathrm{PM}_{10}$ (2-day mean) & 0.17 & $(-0.11 ; 0.46)$ & 0.23 & 0.06 & $(-0.38 ; 0.50)$ & 0.78 & 0.15 & $(-0.22 ; 0.53)$ & 0.42 \\
\hline Ambient $\mathrm{PM}_{10}$ (5-day mean) & 0.50 & $(0.06 ; 0.95)$ & 0.03 & 0.31 & $(-0.43 ; 1.06)$ & 0.40 & 0.34 & $(-0.29 ; 0.97)$ & 0.28 \\
\hline Ambient $\mathrm{PM}_{10}$ (8-day mean) & 0.71 & $(0.18 ; 1.24)$ & 0.01 & 0.83 & $(0.02 ; 1.64)$ & 0.04 & 0.07 & $(-0.72 ; 0.87)$ & 0.86 \\
\hline \multicolumn{10}{|l|}{ Mean arterial pressure $(\mathrm{mmHg})$} \\
\hline Personal PM 2.5 (work hours) & 0.03 & $(-0.11 ; 0.17)$ & 0.66 & -0.01 & $(-0.19 ; 0.18)$ & 0.95 & 0.12 & $(-0.11 ; 0.35)$ & 0.30 \\
\hline Personal EC (work hours) & -0.94 & $(-2.52 ; 0.63)$ & 0.24 & -3.74 & $(-6.70 ;-0.78)$ & 0.01 & 0.51 & $(-1.55 ; 2.57)$ & 0.62 \\
\hline Ambient $\mathrm{PM}_{10}$ (1-day mean) & 0.20 & $(0.01 ; 0.39)$ & 0.04 & 0.12 & $(-0.16 ; 0.41)$ & 0.39 & 0.25 & $(-0.02 ; 0.51)$ & 0.07 \\
\hline Ambient $\mathrm{PM}_{10}$ (2-day mean) & 0.20 & $(-0.07 ; 0.46)$ & 0.14 & 0.05 & $(-0.34 ; 0.44)$ & 0.81 & 0.25 & $(-0.13 ; 0.62)$ & 0.19 \\
\hline Ambient $\mathrm{PM}_{10}$ (5-day mean) & 0.55 & $(0.13 ; 0.96)$ & 0.01 & 0.27 & $(-0.42 ; 0.95)$ & 0.44 & 0.56 & $(-0.05 ; 1.17)$ & 0.07 \\
\hline Ambient $\mathrm{PM}_{10}$ (8-day mean) & 0.81 & $(0.31 ; 1.30)$ & 0.002 & 0.74 & $(0.00 ; 1.48)$ & 0.05 & 0.48 & $(-0.29 ; 1.26)$ & 0.22 \\
\hline \multicolumn{10}{|l|}{ Pulse pressure $(\mathrm{mmHg})$} \\
\hline Personal PM 2.5 (work hours) & -0.06 & $(-0.22 ; 0.10)$ & 0.49 & -0.06 & $(-0.31 ; 0.20)$ & 0.65 & 0.06 & $(-0.20 ; 0.31)$ & 0.65 \\
\hline Personal EC (work hours) & 0.75 & $(-1.12 ; 2.61)$ & 0.42 & 2.69 & $(-1.42 ; 6.8)$ & 0.19 & 0.98 & $(-1.18 ; 3.14)$ & 0.37 \\
\hline Ambient $\mathrm{PM}_{10}$ (1-day mean) & 0.01 & $(-0.22 ; 0.23)$ & 0.96 & -0.03 & $(-0.40 ; 0.33)$ & 0.86 & 0.02 & $(-0.28 ; 0.32)$ & 0.90 \\
\hline Ambient $\mathrm{PM}_{10}$ (2-day mean) & 0.10 & $(-0.21 ; 0.41)$ & 0.51 & -0.10 & $(-0.60 ; 0.40)$ & 0.68 & 0.33 & $(-0.08 ; 0.75)$ & 0.11 \\
\hline Ambient $\mathrm{PM}_{10}$ (5-day mean) & 0.12 & $(-0.38 ; 0.61)$ & 0.64 & -0.26 & $(-1.13 ; 0.60)$ & 0.54 & 0.56 & $(-0.13 ; 1.26)$ & 0.11 \\
\hline Ambient $\mathrm{PM}_{10}$ (8-day mean) & 0.22 & $(-0.37 ; 0.81)$ & 0.46 & -0.38 & $(-1.35 ; 0.59)$ & 0.44 & 1.08 & $(0.27 ; 1.89)$ & 0.01 \\
\hline \multicolumn{10}{|l|}{ Heart rate (bpm) } \\
\hline Personal PM 2.5 (work hours) & 0.15 & $(-0.08 ; 0.39)$ & 0.20 & 0.00 & $(-0.31 ; 0.30)$ & 0.97 & 0.30 & $(-0.14 ; 0.74)$ & 0.18 \\
\hline Personal EC (work hours) & 1.03 & $(-1.62 ; 3.68)$ & 0.44 & -2.08 & $(-6.94 ; 2.79)$ & 0.40 & 2.19 & $(-1.52 ; 5.89)$ & 0.24 \\
\hline Ambient $\mathrm{PM}_{10}$ (1-day mean) & 0.14 & $(-0.19 ; 0.48)$ & 0.40 & -0.03 & $(-0.48 ; 0.41)$ & 0.88 & 0.29 & $(-0.23 ; 0.81)$ & 0.27 \\
\hline Ambient $\mathrm{PM}_{10}$ (2-day mean) & 0.23 & $(-0.23 ; 0.68)$ & 0.33 & -0.14 & $(-0.73 ; 0.46)$ & 0.64 & 0.61 & $(-0.13 ; 1.35)$ & 0.10 \\
\hline Ambient $\mathrm{PM}_{10}$ (5-day mean) & 0.57 & $(-0.14 ; 1.29)$ & 0.12 & -0.13 & $(-1.14 ; 0.89)$ & 0.81 & 1.20 & $(-0.02 ; 2.42)$ & 0.05 \\
\hline Ambient $\mathrm{PM}_{10}$ (8-day mean) & 0.67 & $(-0.20 ; 1.53)$ & 0.13 & -0.44 & $(-1.59 ; 0.71)$ & 0.45 & 1.69 & $(0.27 ; 3.12)$ & 0.02 \\
\hline
\end{tabular}

${ }^{a}$ Adjusted for age, sex, BMI, smoking status, pack-years, number of cigarettes smoked and tea drinking during the study time, usual alcohol drinking, work hours/ week, day of the week, and appropriate outdoor temperature (i.e., temperature averaged over the same time window as the air particle exposure variable).

${ }^{\mathrm{b}}$ For EC, results are estimated on 238 observations because of two missing values; for $\mathrm{PM}_{2.5}$, results are from 239 observations because of one missing value.

${ }^{c}$ For EC exposure, results are estimated on 119 observations because of two missing values.

${ }^{\mathrm{d}}$ For $\mathrm{PM}_{2.5}$ and $\mathrm{EC}$ exposures, results are estimated on 119 observations because of a missing value.

be interpreted in the context of the exposure measures and PM levels found in Beijing. To estimate the effects of PM exposure in the days before the examinations, we used ambient data from the monitor network of the city of Beijing, which measures ambient $\mathrm{PM}_{10}$. $\mathrm{PM}_{10}$ contains both coarse particles, which are mostly filtered out in the upper airways, and fine and ultrafine particles which are considered to be primarily responsible for the cardiovascular effects of PM [1]. $\mathrm{PM}_{2.5}$, which is more widely measured in the North America and Europe, is 
considered a better measure of smaller particles and might more effectively help to capture PM effects [2]. A study that measured different PM fractions in Beijing in the summer of 2006 showed that $\mathrm{PM}_{2.5}$ represented approximately $60 \%$ of ambient $\mathrm{PM}_{10}$ [30]. Therefore, the use of ambient $\mathrm{PM}_{10}$ in our analysis might have contributed to reduce our effect estimates. If the effects that we observed were entirely due to the $\mathrm{PM}_{2.5}$ component, the estimated effect per $10 \mu \mathrm{g} / \mathrm{m}^{3}$ increase in $\mathrm{PM}_{2.5}$ would be about $1.5 \mathrm{mmHg}$, which is well within the range of the summary above.

Moreover, the effect estimates, which we reported as changes in $\mathrm{BP}$ for each $10 \mu \mathrm{g} / \mathrm{m}^{3}$ increase in $\mathrm{PM}_{2.5}$ or $\mathrm{PM}_{10}$, need to be considered against the absolute levels of PM exposure. For instance, the average levels of ambient $\mathrm{PM}_{10}$ in Beijing were approximately $120 \mu \mathrm{g} / \mathrm{m}^{3}$ during our study. As a reference, the average urbanpopulation weighted $\mathrm{PM}_{10}$ in the United States was 19 $\mu \mathrm{g} / \mathrm{m}^{3}$ in the year 2008 [22]. Therefore, due to the high concentrations and wide ranges of PM found in Beijing, even small BP changes for each $10 \mu \mathrm{g} / \mathrm{m}^{3}$ increase in $\mathrm{PM}_{10}$ may correspond to comparatively high overall effects. However, it should also be noted that the doseresponse slope between particles and cardiovascular mortality has been shown to be nonlinear, with lower slopes at higher particle concentrations [31]. Therefore, PM effects might be substantial at low to middle range doses and taper off at higher concentrations.

It is well established that increases in BP of similar magnitude to those that could be attributed to PM exposure in our study in Beijing substantially increase long-term risks of coronary and cerebrovascular events $[4,32]$. However, risks of these events are thought to be related to long-term elevations in BP $[4,32]$. Whether the shorter term effects on BP we observed might contribute to long-term cardiovascular risk or trigger acute cardiovascular events remains to be determined.

In our study, we found increases in BP only in association with the means of ambient $\mathrm{PM}_{10}$ over five or eight days before the examinations. However, we did not find any significant association of BP with the personal measures of $\mathrm{PM}_{2.5}$, which were taken during the 8hour work shift immediately preceding the BP measures. Our results indicate delayed or cumulative effects of PM on BP. Consistent with our findings, most previous studies have shown that BP increases only days (lags two to five) after an elevation in ambient PM or even following a longer duration of higher exposure levels (up to 30 days) [29]. For instance, Ibald-Mulli et al. [8] showed a significant increase in systolic BP in a study of 2607 adults in Augsburg, Germany associated with the mean of total suspended particles in the previous five days. Zanobetti et al. [9] found significant increases in systolic and diastolic BP in cardiac rehabilitation patients related to the average $\mathrm{PM}_{2.5}$ in the previous five days. Effects on BP have been associated with 7-day averages in the Normative Aging Study [33], and with even longer averages in Multi-ethnic Study of Atherosclerosis [6]. However, several other observational studies have also found correlations between exposures and BP with shorter time lags $[6,7,20]$. In addition, in an cross-over randomized trial, Langrish et al. [34] showed that wearing a facemask for two hours to reduce air pollution exposure while walking in central Beijing reduced systolic BP. Differences in the study methods and design, levels of co-pollutants and their correlations with PM, and different characteristics of the study populations may account for the discrepancies in the results.

The inclusion of truck drivers and indoor office workers in our study was specifically designed to identify the effects of work-related traffic exposures on BP. However, in covariate-adjusted analyses we did not find any significant difference in BP between the two groups. Also, the levels of personal EC, a tracer of particle emissions from traffic, did not show any positive correlations with BP. In fact, EC showed a paradoxical negative association with diastolic and mean BP when the analysis was restricted to indoor office workers. Therefore, our results do not allow linking the effects of PM exposure on BP specifically to traffic emissions.

Our study had the advantage to have both personal and ambient measures of air pollution. All participants were evaluated with standard protocols for exposure assessment and measurement of BP. We conducted technical validation of personal $\mathrm{PM}_{2.5}$ measures that showed high reproducibility $(r=0.944)$ of our measurements. By measuring EC - a tracer of traffic particles - as well as by evaluating a group, i.e. truck drivers with direct exposure to traffic, we had the opportunity to distinguish the effects of traffic pollution from those of the general levels of ambient PM in Beijing. We also recognize that our study is subject to a number of limitations. Because of the relatively small sample size, we cannot exclude false negative findings as well as chance findings. Our results included some unexpected results, for instance, the finding of a negative association of EC with diastolic BP and mean arterial pressure among office workers. The literature regarding the association between BP and EC (or black carbon, [BC], which is highly correlated to EC) is limited and inconsistent. Mordukhovich et al. [33] found $\mathrm{BC}$ to be positively associated with systolic and diastolic BP in a cohort of elderly men. A study of 16 elderly subjects with respiratory disease showed no association between $\mathrm{BC}$ and blood pressure [19]. In a study with 62 cardiac rehabilitation patients, BC was positively associated with resting diastolic BP in single-pollutant models, but this association was found to be confounded by $\mathrm{PM}_{2.5}$ [9]. Further research is warranted to determine whether $\mathrm{EC} / \mathrm{BC}$ is a determinant of increased 
BP. Our study was conducted in a short period of time in the summer of 2008. In a study of 10,459 individuals in South Korea, Choi et al. [7] showed stronger effects of PM exposure on BP during the warm season. Whether our findings can be extended to the winter season in Beijing remains to be determined. Although we used matching and multivariable models to control potential confounders, we cannot exclude residual confounding from measured and unmeasured variables, including different types of tea consumption and common activities conducted by the two groups during their work days. In addition to using personal $\mathrm{PM}_{2.5}$ and EC measures, we have utilized stationary measures of ambient $\mathrm{PM}_{10}$ to represent exposures. Simulation studies have shown that the error introduced by using data from stationary monitors is highly unlikely to bias away from the null, and indicated that this exposure misclassification may lead to an underestimation of the health effects of air pollution [35]. In addition, serial measures of ambient particulate concentrations have been shown to be representative of variations in personal exposures [36], particularly in the presence of high ambient PM levels [37].

\section{Conclusions}

Our results showed a delayed effect of PM exposure on $\mathrm{BP}$ in individuals with high exposure to particulate pollution. The lack of associations with personal $\mathrm{PM}_{2.5}$ and EC measured during work hours indicates that effects on BP may be better captured with more protracted monitoring of air pollution levels in days before examination. Further investigations are warranted to estimate the impact of PM-related changes in BP on cardiovascular morbidity and mortality. Our results provide further support for the urgent implementation of measures for exposure reductions in the Beijing metropolitan area, as well as in areas with similarly high PM levels worldwide.

\section{Additional material}

Additional file 1: Additional Tables Table S1 Stratified analyses by current smoking on all subjects (office workers and truck drivers) The results were stratified by current smoking for the associations of personal $\mathrm{PM}_{2.5}$, personal $\mathrm{EC}$, and ambient $\mathrm{PM}_{10}$ with $\mathrm{BP}$ and heart rate for the entire study group. Table S2 Stratified analyses by current smoking on office workers The results were stratified by current smoking for the associations of personal $\mathrm{PM}_{2.5}$, personal EC, and ambient $\mathrm{PM}_{10}$ with BP and heart rate for office workers. Table S3 Stratified analyses by current smoking on truck drivers The results were stratified by current smoking for the associations of personal $\mathrm{PM}_{25}$, personal $\mathrm{EC}$, and ambient $\mathrm{PM}_{10}$ with $\mathrm{BP}$ and heart rate for truck drivers.

\section{List of abbreviations}

BP: Blood Pressure; BTDAS: Beijing Truck Driver Air Pollution Study; Cl: Confidence Interval; EC: Elemental Carbon; PM: Particulate Matter; PM 2.5 : particulate matter $\leq 2.5 \mu \mathrm{m} ; \mathrm{PM}_{10}$ : particulate matter $\leq 10 \mu \mathrm{m} ; \mathrm{SD}$ : Standard Deviation.

\section{Acknowledgements}

This work was supported by US EPA (R-82735301); NIEHS (ES00002 and R21ES020010); CARIPLO Foundation (2007-5469); Italian Ministry of Scientific Research (PRIN 2007-2S2HT8).

\section{Author details}

${ }^{1}$ Department of Environmental Health, Harvard School of Public Health, Boston, Massachusetts, USA. ${ }^{2}$ Department of Occupational and Environmental Health, University of Milan and Fondazione IRCCS Ca' Granda Policlinico, Milan, Italy. ${ }^{3}$ Deptartment of Safety Engineering, China Institute of Industrial Health No.45 Zengguang Rd., Haidian District, Beijing 100048, China. ${ }^{4}$ Department of Preventive Medicine, Feinberg School of Medicine, Northwestern University, Chicago, Illinois, USA. ${ }^{5}$ Center for Health Studies, Universidad del Valle de Guatemala, Guatemala City, Guatemala.

${ }^{6}$ Department of Occupational and Environmental Health, Peking University Health Science Center, Beijing, China.

\section{Authors' contributions}

$A B, S W, C D, P A B, J S$, and $L H$ designed the study and supervised the study operations. $C D, J P M, A D$, and $X Z$ prepared the study protocols and oversaw their implementation. FB performed the statistical analyses. $A B$ and $L H$ wrote the manuscript. All authors provided edits and comments to the manuscript. All authors read and approved the final manuscript.

\section{Competing interests}

The authors declare that they have no competing interests.

Received: 19 August 2011 Accepted: 21 December 2011

Published: 21 December 2011

\section{References}

1. Brook RD, Rajagopalan S, Pope CA, Brook JR, Bhatnagar A, Diez-Roux AV Holguin F, Hong Y, Luepker RV, Mittleman MA, Peters A, Siscovick D, Smith SC Jr, Whitsel L, Kaufman JD: Particulate matter air pollution and cardiovascular disease: An update to the scientific statement from the American Heart Association. Circulation 2010, 121(21):2331-2378.

2. USEPA: Policy Assessment for the Review of the Particulate Matter National Ambient Air Quality Standards. Research Triangle Park, NC: Office of Air Quality Planning and Standards; 2011.

3. Stamler J, Stamler R, Neaton JD: Blood pressure, systolic and diastolic, and cardiovascular risks. US population data. Arch Intern Med 1993, 153(5):598-615.

4. van den Hoogen PC, Feskens EJ, Nagelkerke NJ, Menotti A, Nissinen A, Kromhout D: The relation between blood pressure and mortality due to coronary heart disease among men in different parts of the world. Seven Countries Study Research Group. N Engl J Med 2000, 342(1):1-8.

5. McCracken JP, Smith KR, Diaz A, Mittleman MA, Schwartz J: Chimney stove intervention to reduce long-term wood smoke exposure lowers blood pressure among Guatemalan women. Environ Health Perspect 2007, 115(7):996-1001.

6. Auchincloss AH, Diez Roux AV, Dvonch JT, Brown PL, Barr RG, Daviglus ML, Goff DC, Kaufman JD, O'Neill MS: Associations between recent exposure to ambient fine particulate matter and blood pressure in the Multiethnic Study of Atherosclerosis (MESA). Environ Health Perspect 2008, 116(4):486-491.

7. Choi JH, Xu QS, Park SY, Kim JH, Hwang SS, Lee KH, Lee HJ, Hong YC: Seasonal variation of effect of air pollution on blood pressure. $J$ Epidemiol Community Health 2007, 61(4):314-318.

8. Ibald-Mulli A, Stieber J, Wichmann HE, Koenig W, Peters A: Effects of air pollution on blood pressure: a population-based approach. Am J Public Health 2001, 91(4):571-577.

9. Zanobetti A, Canner MJ, Stone PH, Schwartz J, Sher D, Eagan-Bengston E, Gates KA, Hartley LH, Suh H, Gold DR: Ambient pollution and blood pressure in cardiac rehabilitation patients. Circulation 2004, 110(15):2184-2189.

10. Hampel R, Lepeule J, Schneider A, Bottagisi S, Charles MA, Ducimetiere P, Peters A, Slama R: Short-term Impact of Ambient Air Pollution and Air Temperature on Blood Pressure Among Pregnant Women. Epidemiology 2011.

11. Liu L, Ruddy T, Dalipaj M, Poon R, Szyszkowicz M, You H, Dales RE, Wheeler AJ: Effects of indoor, outdoor, and personal exposure to 
particulate air pollution on cardiovascular physiology and systemic mediators in seniors. J Occup Environ Med 2009, 51(9):1088-1098.

12. Brook RD, Urch B, Dvonch JT, Bard RL, Speck M, Keeler G, Morishita M, Marsik FJ, Kamal AS, Kaciroti N, Harkema J, Corey P, Silverman F, Gold DR, Wellenius G, Mittleman MA, Rajagopalan S, Brook JR: Insights into the mechanisms and mediators of the effects of air pollution exposure on blood pressure and vascular function in healthy humans. Hypertension 2009, 54(3):659-667.

13. Brook RD, Bard RL, Burnett RT, Shin HH, Vette A, Croghan C, Phillips M, Rodes C, Thornburg J, Williams R: Differences in blood pressure and vascular responses associated with ambient fine particulate matter exposures measured at the personal versus community level. Occup Environ Med 2011, 68(3):224-230.

14. de Paula Santos U, Braga AL, Giorgi DM, Pereira LA, Grupi CJ, Lin CA, Bussacos MA, Zanetta DM, do Nascimento Saldiva PH, Filho MT: Effects of air pollution on blood pressure and heart rate variability: a panel study of vehicular traffic controllers in the city of Sao Paulo, Brazil. Eur Heart 2005, 26(2):193-200.

15. Ibald-Mulli A, Timonen KL, Peters A, Heinrich J, Wolke G, Lanki T, Buzorius G, Kreyling WG, de Hartog J, Hoek G, ten Brink HM, Pekkanen J: Effects of particulate air pollution on blood pressure and heart rate in subjects with cardiovascular disease: a multicenter approach. Environ Health Perspect 2004, 112(3):369-377.

16. Madsen C, Nafstad P: Associations between environmental exposure and blood pressure among participants in the Oslo Health Study (HUBRO). Eur J Epidemiol 2006, 21(7):485-491.

17. Brauer M, Ebelt ST, Fisher TV, Brumm J, Petkau AJ, Vedal S: Exposure of chronic obstructive pulmonary disease patients to particles: respiratory and cardiovascular health effects. J Expo Anal Environ Epidemiol 2001, 11(6):490-500

18. Harrabi I, Rondeau V, Dartigues JF, Tessier JF, Filleul L: Effects of particulate air pollution on systolic blood pressure: A population-based approach. Environ Res 2006, 101(1):89-93.

19. Jansen KL, Larson TV, Koenig JQ, Mar TF, Fields C, Stewart J, Lippmann M: Associations between health effects and particulate matter and black carbon in subjects with respiratory disease. Environ Health Perspect 2005, 113(12):1741-1746

20. Linn WS, Gong H, Clark KW, Anderson KR: Day-to-day particulate exposures and health changes in Los Angeles area residents with severe lung disease. J Air Waste Manag Assoc 1999, 49(9 Spec No):108-115.

21. Urch B, Silverman F, Corey P, Brook JR, Lukic KZ, Rajagopalan S, Brook RD: Acute blood pressure responses in healthy adults during controlled air pollution exposures. Environ Health Perspect 2005, 113(8):1052-1055.

22. World Development Indicators. [http://data.worldbank.org/data-catalog/ world-development-indicators].

23. Yu Y, Schleicher N, Norra S, Fricker M, Dietze V, Kaminski U, Cen K, Stuben D: Dynamics and origin of PM2.5 during a three-year sampling period in Beijing, China. J Environ Monit 2011, 13(2):334-346.

24. ISO: ISO 9835, Ambient air - Determination of a black smoke index. Geneva: International Organization for Standardization; 1993.

25. Kinney PL, Aggarwal M, Northridge ME, Janssen NA, Shepard P: Airborne concentrations of PM(2.5) and diesel exhaust particles on Harlem sidewalks: a community-based pilot study. Environ Health Perspect 2000, 108(3):213-218.

26. Janssen NA, van Vliet PH, Aarts F, Harssema H, Brunekree B: Assessment of exposure to traffic related air pollution of children attending schools near motorways. Atmospheric Environment 2001, 35(22):3875-3884.

27. NOAA: NNDC Climate Data Online. US Department of Commerce; 2011.

28. Alpert B, McCrindle B, Daniels S, Dennison B, Hayman L, Jacobson M, Mahoney L, Rocchini A, Steinberger J, Urbina E, Williams R: Recommendations for blood pressure measurement in human and experimental animals; part 1: blood pressure measurement in humans. Hypertension 2006, 48(1):e3, author reply e5.

29. Brook RD, Rajagopalan S: Particulate matter, air pollution, and blood pressure. J Am Soc Hypertens 2009, 3(5):332-350

30. Zhang WJ, Sun YL, Zhuang GS, Xu DQ: Characteristics and seasonal variations of PM2.5, PM10, and TSP aerosol in Beijing. Biomed Environ Sci 2006, 19(6):461-468.

31. Pope CA, Burnett RT, Krewski D, Jerrett M, Shi Y, Calle EE, Thun MJ: Cardiovascular mortality and exposure to airborne fine particulate matter and cigarette smoke: shape of the exposure-response relationship. Circulation 2009, 120(11):941-948.

32. Lewington S, Clarke R, Qizilbash N, Peto R, Collins R: Age-specific relevance of usual blood pressure to vascular mortality: a meta-analysis of individual data for one million adults in 61 prospective studies. Lancet 2002, 360(9349):1903-1913.

33. Mordukhovich I, Wilker E, Suh H, Wright R, Sparrow D, Vokonas PS, Schwartz J: Black carbon exposure, oxidative stress genes, and blood pressure in a repeated-measures study. Environ Health Perspect 2009, 117(11):1767-1772

34. Langrish JP, Mills NL, Chan JK, Leseman DL, Aitken RJ, Fokkens PH, Cassee FR, Li J, Donaldson K, Newby DE, Jiang L: Beneficial cardiovascular effects of reducing exposure to particulate air pollution with a simple facemask. Part Fibre Toxicol 2009, 6:8.

35. Zeger SL, Thomas D, Dominici F, Samet JM, Schwartz J, Dockery D, Cohen A: Exposure measurement error in time-series studies of air pollution: concepts and consequences. Environ Health Perspect 2000, 108(5):419-426.

36. Wilson WE, Brauer M: Estimation of ambient and non-ambient components of particulate matter exposure from a personal monitoring panel study. J Expo Sci Environ Epidemiol 2006, 16(3):264-274.

37. Avery CL, Mills KT, Williams R, McGraw KA, Poole C, Smith RL, Whitsel EA: Estimating error in using ambient PM2.5 concentrations as proxies for personal exposures: a review. Epidemiology 2010, 21(2):215-223.

doi:10.1186/1476-069X-10-108

Cite this article as: Baccarelli et al:: Effects of particulate air pollution on blood pressure in a highly exposed population in Beijing, China: a repeated-measure study. Environmental Health 2011 10:108.

\section{Submit your next manuscript to BioMed Central and take full advantage of:}

- Convenient online submission

- Thorough peer review

- No space constraints or color figure charges

- Immediate publication on acceptance

- Inclusion in PubMed, CAS, Scopus and Google Scholar

- Research which is freely available for redistribution

Submit your manuscript at www.biomedcentral.com/submit
Ciomed Central 